\title{
Dystocia Associated with Abortion due to Twin Pregnancy in Pluriparous Murrah Buffalo
}

\author{
Navgeet Singh*, S.S. Dhindsa, Navjot Singh, Arashdeep Kaur and Prahlad Singh
}

Department of Veterinary Gynaecology and Obstetrics, College of Veterinary Science, Guru Angad Dev Veterinary and Animal Sciences University, Ludhiana - 141004, Punjab, India

*Corresponding author

A B S T R A C T

\section{Keywords \\ Abortion, Twinning, Buffalo \\ Article Info \\ Accepted: \\ 26 October 2018 \\ Available Online: \\ 10 November 2018}

A murrah buffalo in third parity was presented in eighth month of gestation with the history of vaginal discharge from past two days. Per vaginal investigations done to diagnose the etiology suggested fully dilated cervix with the presence of twin fetuses. Taking into consideration, the unsuccessful delivery attempts by the animal, it was decided to obstetrically intervene, which led to the birth of dead male co-twins.

\section{Introduction}

In general, multiple calvings are considered more difficult than single ones in bovine (Zaborski et al., 2009). Twins are also reported to reduce the breeding efficiency of dairy as well as beef animals (Cobanoglu, 2010). Twin calves are known to be lighter in weight as compared to single births (Gregory et al., 1996). However, the higher incidence of dystocia with twin births is due to malpresentation of one fetus (Gregory et al., 1996) or simultaneous presentation of both fetuses (Kirkpatrick, 2002). Also, the gestation length in case of twin pregnancy is considered less as compare to single pregnancy which sometimes terminates early in the third trimester and may mimic an abortion and are mostly associated with dystocia (HosseinZadeh, 2010). Twins can either be monozygotic which are always of same sex or dizygotic which can be of either sex. The present case reports similar findings, where abortion due to twin pregnancy in eighth month of gestation was observed in a pluriparous murrah buffalo and its successful clinical management has been discussed.

\section{Case History and Observations}

A pluriparous murrah buffalo in third parity was presented to the university veterinary hospital in eighth month of gestation with the chief complaint of vaginal discharge and straining from past two days. Basic parameters such as respiration rate, pulse rate and 
temperature were observed to be in normal range. Further investigations done to diagnose the etiology of the ailment suggested fully dilated cervix and simultaneous presence of two fetuses which appeared separate and did not seem to be conjoined in any way. Taking into consideration the unsuccessful delivery attempts by the animal and simultaneous presence of twin fetuses together, it was decided to intervene obstetrically and relieve the suffering to the animal.

\section{Treatments and Discussion}

Following epidural anaesthesia with $2 \%$ Lignocaine hydrochloride $(5 \mathrm{ml})$ solution and ample lubrication using $1 \%$ sodium carboxy methyl cellulose solution, obstetrical maneuvers were performed which included securing the forelimbs and head of one fetus in order to apply traction while simultaneously repelling the other fetus to make space for easing the delivery of one fetus. This led to delivery of one fetus after which the second fetus was delivered easily by mild traction at forelimbs and head. In this way, per vaginal delivery of twin fetuses became possible by obstetrical interventions. After delivery, it was found that both the fetuses were of male sex and well-formed lacking any distinct abnormality (Fig. 1). Post-obstetrical treatment involved a complete course of antibiotic, analgesic cum anti-inflammatory along with supplemental therapy for a period of five days.

Fig.1 Twin fetuses after their per-vaginal delivery

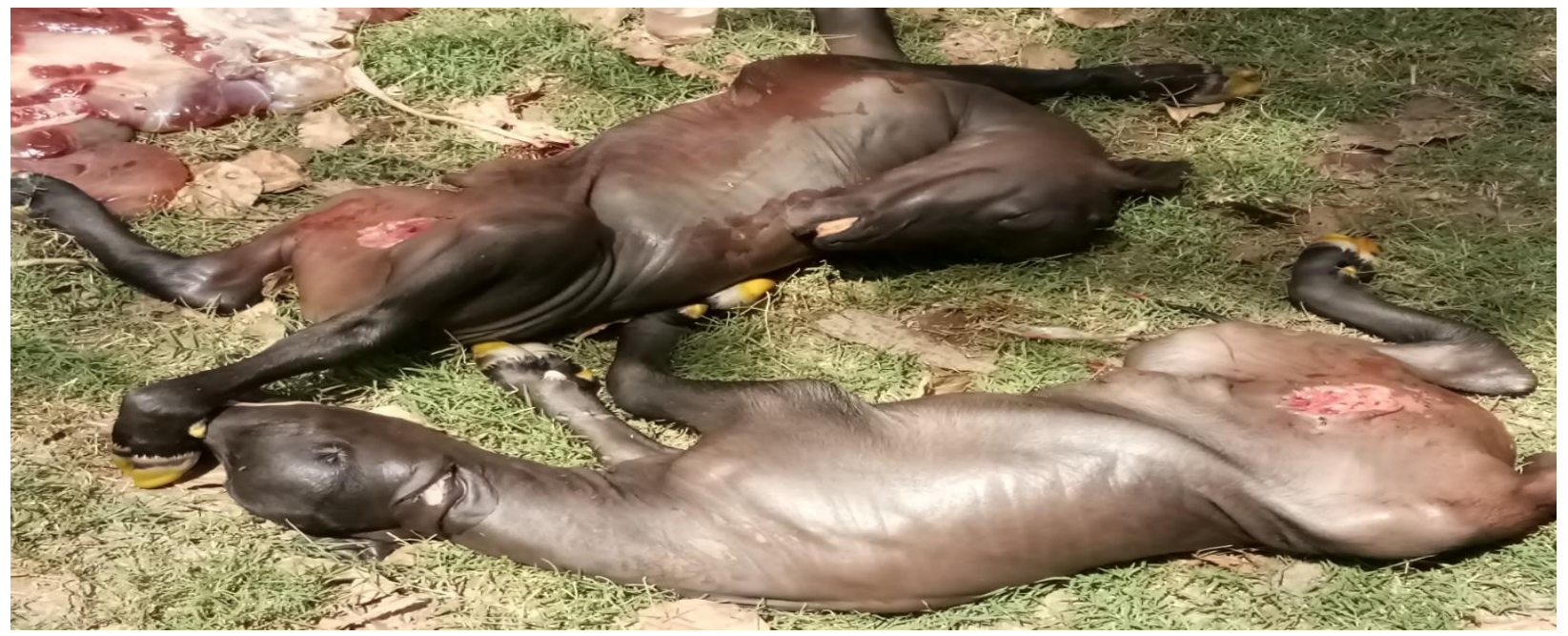

Twin birth is an unavoidable condition in dairy animals since several factors such as breed, genetics, parity and some other environmental effects greatly influence twinning rate. Although the evidence of twin pregnancies is limited in buffalo, but as reported in Holstein cows, twin pregnancies result in 10.5 times higher probability of dystocia compared to single calvings (Correa et al., 1993). Twin pregnancies should be diagnosed carefully so as to avoid misinterpreting twins as monsters. Moreover, while performing obstetrical intervention, one fetus should be repelled while the other is delivered by traction.

\section{References}

Cobanoglu, O., 2010. Twinning in cattle: Desirable or undesirable? J. Biol. Environ. Sci. 4:1-8. 
Correa, M.T., Erb, H., and Scarllet, J. 1993. Path analysis for seven post-partum disorders of Holstein cows. J. Dairy Sci. 76:1305-1312.

Gregory, K.E., Echternkamp, S.E., and Cundiff, L.V. 1996. Effects of twinning on dystocia, calf survival, calf growth, carcass traits and cow productivity. $\mathrm{J}$. Anim. Sci. 74: 1223-1233.

Hossein-Zadeh, N.G. 2010. The effect of twinning on milk yield, dystocia, calf birth weight and open days in Holstein dairy cows of Iran. J. Anim. Physiol. Anim. Nutr. (Berl).94:780-787.

Kirkpatrick, B.W. 2002. Management of twinning cow herds. J. Anim. Sci. 80:14-18.

Zaborski, D., Grzesiak, W., and Szatkowska, I. 2009. Factors affecting dystocia in cattle. Reprod. Dom. Anim. 44: 540551 .

\section{How to cite this article:}

Navgeet Singh, S.S. Dhindsa, Navjot Singh, Arashdeep Kaur and Prahlad Singh. 2018. Dystocia Associated with Abortion due to Twin Pregnancy in Pluriparous Murrah Buffalo. Int.J.Curr.Microbiol.App.Sci. 7(11): 3381-3383. doi: https://doi.org/10.20546/ijcmas.2018.711.387 